\title{
灵动的课堂 生命的绽放
}

\author{
蔡菊 \\ 重庆市奉节中学校 \\ DOI:10.32629/jief.v2i6.1015
}

[摘 要] 我看到的是孩子们的进步, 感受的是他人所体验不到的做教师的幸福……其中教师的幸福感是最重要的要素, 它会感染到学生年幼 的心灵。幸福地做教师, 就是教师在从事教育教学工作的时候感受到这个职业可以满足自己的需要, 能够实现自身的价值, 并且能够产生愉 悦的感觉。

[关键词] 幸福地做教师; 自身的价值; 愉悦的感觉

中图分类号: G623.2 文献标识码: A

一九九八年我中师毕业, 带着满腔激情走上了那神圣的三尺讲台, 从教以来, 我热爱教育事业, 热爱我的学生, 工作踏实勤奋。当教师十 五年来, 但一直被一个问题所困惑着, 那就是同事们经常谈论的一个话 题: “上课好难得讲啊! 当老师, 快乐吗? 幸福吗? ” 其实在那一段时 间里, 我也是迷茫的、彷得的, 总觉得做教师好累, 因为教师在课堂上 讲的声嘶力竭, 而学生在下面似听非听, 现在的初中生就有着非常明显的 感觉, 上课的时候, 老师一个人在上面讲, 总是有的学生不听, 无论用 什么样的方法, 也是很难调动学生的兴趣, 课堂沉问, 无趣。面对这样 的教学现状, 我下定决心一定要打破这种传统的教育模式, 不能让学生 高压、被动的学, 不能控制他们的生命。

在推行新课改的春风里, 我率先实行了新课改生本教育, 灵动课堂 就是激昂生命, 就是让学生享受、快乐、主动的内在的学习。在我实施 灵动课堂将近一年的实践中, 给我的是无限的幸福与感动。

\section{1 灵动激活了我的课堂}

2013 年 9 月我又新接了七年级新生, 由于我校处于城郊, 优生的流 失率比较大, 所以接手的这个班级的基础比较差, 班里还有几个学生的 小学毕业成绩只有个位数, 看到学生这样的基础, 我绞尽脑汁, 经过半 学期的 “保姆式” “灌输式” “填鸭式” 的教育方法, 但我感觉学生并 不领情, 已经失去了刚进校的那份激情, 举手发言的热情越来越少了, 课堂沉闷、呆板, 感觉学生学习起来挺吃力的, 而且班上还有一位自闭 症的孩子, 从进校都还没开口说话, 我第一次感觉到我这个班主任好失 败, 面对这样的情景, 我焦急, 不知所措, 我该怎样去教育他们? 怎样 才能找到一把开启他们心灵的钥匙? 怎样才能让孩子们在课堂大胆的动 起来? 怎样才能让他们能有所进步? 一次偶然的机会, 我恍然大悟, 原 来数学课可以这样上, 班主任也可以这样当, 生本教育走进了我的课堂。

1.1 启动灵动, 组建小组

生本教育的第一环节就是要建立好小组, 我采用了组间同质, 组内 异质的方法进行了分组, 每组六人, 共十组, 每个组员都担任了不同的 角色, 分别为: 组长 (分派任务, 领头小组学习), 副组长 (为学科老师 评价提供依据）、记录员（记录、评价）、资料员（准备、查阅资料）、 汇报员（汇报学习情况、成果）, 纪检员（检查、督促作业完成情况及 小组纪律情况）。每位组员都必须严格的履行自己的职责。

组建一个组就是一个整体, 是一个家, 小组成员之间要团结。组长 必须积极主动地与组员交流情感, 从细节之处去关心他们, 帮助他们克 服困难, 帮助他们树立信心, 每位孩子都遵从自己的小组口号来实现自 己的目标。

1.2 灵动践行, 递进训练
第一学期的后半期, 我就全面地实行了小组合作的教学方法, 在开 始启动的过程中, 孩子们总是很被动的, 根本就没有主动参与学习、回 答问题的习惯, 于是我首先实施以下步骤来引导学生大胆学习。

1.2. 1 启动组长的潜力

每一节课, 首先要求组长带领组员先进行自学 8 分钟, 然后各组的 组长必须带头起来解决有关问题, 就这样大约进行了两周的训练, 以后 的每节课组长都能主动起来解决问题了, 同时课堂氛围也越来越来活跃 了。心理学家罗杰斯说: “没有人能教会任何人任何东西。”也就是说: 学生学会任何东西, 最终都要通过自己的内化, 因而, 这个最后过程并 不是老师完成的。

1.2 .2 组长带兵的训练

因为生本教育的理念是激扬生命, 让学生主动、内在的学, 不是让 少数学生主动、内在的学, 而是让大多数乃至全班学生都能主动、内在 的学, 当然这需要一个过程, 面对我班学生的实际情况, 于是我采用了 让组长在两个星期内, 发动自己组内的一位组员要站起来回答问题, 这 当然就要靠组长的能力去实施了, 经过组长的努力和组员的支持与配合, 两周后就有六个组中的组员能起来回答问题了。但还有四个小组还是存 在问题, 于是我就跟这四个组的组长进行了交流, 到底是什么原因你们 组内没有人愿意起来回答问题, 有组长告诉我说: “他们主要是因为胆小, 不敢站起来回答问题, 又怕答错了, 会遭到老师的批评” 等一些情况。 我了解这些情况后, 就又跟这些孩子们就行亲切的交流, “老师采用这 种教学方法的目的就是为了让你们动口, 让你们动脑, 课堂是你们的, 不要害怕, 就是答错了, 老师不会批评你, 你就大胆的说吧” ! 就这样 通过我与这些孩子们沟通后, 效果就明显好多了, 许多孩子都争先恐后 的起来回答问题了, 课堂活跃了。学习本身应是快乐的, 知识的获得, 想象的拓展, 思维的升华, 其中蕴涵着无穷的乐趣。

\section{2 .3 兵带兵的快乐训练}

“灵动课堂” 理念的核心就是 “一切为了学生, 高度尊重学生, 全面 依靠学生为宗旨的教育”。现在是可以全面铺开的时候了, 要求兵带兵 的强化训练, 所以在后面的教学中, 我要求组长在两个月内让各组的组 员都能快乐的参与到我们的学习中来, 上课都能积极的回答问题, 能快 乐参与, 快乐展示。在第二学期半期时, 班上所有的学生都能起来回答 问题了, 就是班上那位所谓的自闭症的孩子, 也开口回答问题了, 这给 予了我好大的欣慰, 虽然还是有极少一部分的孩子们回答问题的次数屈 指可数, 但这对他们来说你真的就是一次成功, 我始终相信, 只要坚持, 就一定会有奇迹。

教书育人的根本目的, 不仅仅是 “传道, 授业, 解惑” , 也不仅仅 
是为社会培养 “人材”, 其根本目的应是提升一个人的生命质量, 让学 生成长为自由的, 全面发展的人。

1.3 灵动课堂, 环环紧扣

灵动课堂就是要充分信任学生, 相信学生, 敢于放手, 并真正依靠 学生自主地学; 善于创设能激发学生学习欲望的教学情境; 注重小组合 作的学习方式, 积极创设和谐的学习环境。快乐学习知识, 快乐的成长, 使他们真正的成为学习的主人。但为了让学生在学习的过程始终充满那 份热爱与激情, 我的课堂主要体现四个重要的环节

\section{3.1 自学主动}

自主学习使学生真正成为学习的主人, 自主学习能培养学生充分的 自信心, 一个自信的人, 总是会精神饱满地去迎接挑战、战胜困难的。 根据本节课的教学目标, 设置与本节课内容紧密联系的问题, 让学生带 着问题进行八分钟的自主学习, 其实在学生学习当天内容时, 在前一天 要对学生布置提前预习第二天的新课, 这样在进行上新课时, 这个自主 学习就更加的加深了学生的理解, 同时学生也能顺利的完成第一个环节。 自主学习完毕后, 就由代表解决自学中设置的问题。在整个自主学习地 过程中, 我重视每一个学生的观点和问题, 课堂上洋溢着宽松和谐、探 索进取的气氛。对好的方面予以肯定和表扬, 对出错者予以耐心指导和 鼓励。

关注学生的学习过程, 学生得到了充分重视, 体验到了成功的乐趣, 自信心增强了, 学习的兴趣也就更大了。

\section{3.2 交流互动}

合作学习就是要体会团队合作精神, 由于学生有了先自学的基础, 回到课堂, 就可以进行小组交流。由于每个学生都有自己的研究心得 (无 论多少, 无论对错), 都想在同伴面前 “炫耀” , 此时课堂上教师就要 给学生这样的展示机会。有人提出, 小组中有学生不学怎么办? 瞎学怎 么办? 调皮捣蛋怎么办? 生本教育实践者告诉我们, 小组讨论其实在形 成一种互相帮助、互相交流、合作学习的课堂文化氛围。即向别人求教 是光彩的, 能帮助别人的是好学生。同时, 教师的教学管理、评价方式 也要随之发生改变。我通过颁发小红旗、评选 “优秀小组” 的方式, 促 进 6 人小组成员之间的互帮互学。当学生通过组内交流、互相帮助, 全 组同学都学会之后, 就可以获得 “优秀小组”。这个小组的合作学习气 氛一定会很快地成长起来.

\subsection{2 展示生动}

展示评价是引导学生在现有基础上的进步, 激发学生的欲望, 启发 学生的思维。通过学生完成当堂相关的练习, 为了巩固达标情况, 学生 完成作业以后, 首先让学生在小组内自评、互评, 然后各小组代表在全 班展示, 并接受全班同学的评价, 在展示的过程中, 不仅仅针对优秀的 进行展示, 也要对出现的问题进行展示, 要让学生记住出现错误的原因, 这样有利于提醒学生需要注意的问题。学生在评价的过程也是相当的积 极, 争先恐后的跑上讲台, 这样的课堂学生没有压力, 学的轻松, 学的 快乐, 其实我也感到无比的幸福。

\section{2 灵动课堂激扬了学生的斗志}

生本教育真的为孩子指明了前进的方向, 为了培养学生综合素质, 我要求组长创建自己组内的文化, 例如: 创建自己组内的组歌, 诗歌。 每一个月利用班会展示, 展示优秀的可以奖励小红旗, 以下就是每个小 组的文化与组歌。

案例一: 不低头, 更精彩的活

2014 年 5 月 9 日 星期五 晴

又到了周五, 和往常不同的是, 今晚决定展示小组文化, 当然我们
超越自我组每个人都信心百倍, 轮到我们上台展示了, 刚开始心里还有 点志忈, 但唱着唱着就渐入佳境了, 虽然其中有一点点小瑕疪, 但今天 我真的很高兴, 每个人为了小组的荣誉, 努力奋搏, 尤其是蔡梦辉的那 句: “让我不低头, 更精彩的活”, 让我们每个人都惊叹了, 希望超越 自我的所有成员在以后的日子里变得更加的优秀。

案例二: 我们都要成为闪光的金子

2014 年 4 月 23 日 星期三 晴

还没有进入初中时, 我是一个活泼好动的女孩, 可进入初中生活后, 可能是学习课程的增多, 我失去了以往的活泼好动, 变得有些成熟了, 也变得坚强了, 怎样学会忍才能成大器, 我是一个很好强的人, 别人也 看得出来, 在每一件事上都争做最好, 学习亦是如此, 我经不起甚至害 怕老师骂我, 我在这一方面真的很脆弱。

在小学, 我的学习成绩不敢说拔尖, 但也算优秀, 我一直很想突破 自己, 做到最好, 但一直没能突破, 自从蔡老师采用 “成长记录袋” 这 种激励评价方式和高效的 “生本教育” 模式后, 我一点一点在进步, 而 且也锻炼另外我的能力, 现在走上讲台我也不再紧张, 如果坚持这种教 育模式, 三年后, 每一个人都会成为闪光的金子, 我真的很感谢蔡老师, 感谢她给了我们施展才华的机会, 平时, 老师讲完课或者布置作业, 我 都会利用课余时间, 完成作业, 每次上的新课, 我也会提前预习, 可是 总觉得少了一些勤奋, 老师早中晚都有规定时间到班, 我也很准时进教 室, 看看书, 写写作业, 我自身还有很多缺点, 希望随着时光流逝, 我 不断成长, 缺点会一点一点变成优点, 超越自我, 会变得更加优秀!

\section{2 灵动课堂给予我的感动}

孩子们在学习中找到了自信, 找回了成功的勇气, 同时我也收获了 许多感动。

\section{案例一: 温暖 幸福 感动}

我的办公桌上时时就会收到孩子们制作的小红花、千纸鹤, 精美的 卡片, 温馨的纸条, 还有温暖的留言, 留言中写道: “老师, 您的这种 教学方法很好, 我学的很轻松, 胆量也大了, 我敢发言了, 谢谢你! 老 师, 你让我找到了自信”。“有人说千纸鹤代表平安, 我的手工不好, 但这是我真诚的心意, 祝: 老师, 平平安安” “老师, 感谢有您! 作为 您的学生真的感到很幸运, 您用知识的甘露浇开了我们理想的花朵, 您 用心灵的清泉孕育了我们情操的美果, 老师, 我们真的很爱您” ! …… 孩子们真诚的话语, 让我感动、幸福。精神的力量是无穷的! 虽然没有 人能左右我们的命运, 但是一句重要的话语有时就如同人生的一颗启明 星, 温暖我们心灵的港湾, 照亮我们前行的路程 。

《爱上数学, 精彩无限》陈春艳

曾经懜懂, 曾经无谓, 曾经欢歌, 曾经哭泣 $\cdots$ 我以前的数学很差, 很苦恼不知道怎样才能把成绩提起来, 突然一天, 我改变了对数学的看 法, 因为我可亲可爱的蔡老师改变了传统的教育方法, 现在采用了生本 教育方法, 这样的课堂真正的让我找到了自信, 有了勇气, 而且我也当 上了学习组长, 我的成绩飞跃, 现在还可以给全班同学讲题, 我感受到 数学的精彩, 内心的愉快。

\section{[参考文献]}

[1]刘丽萍.打造 “灵动课堂” 发展小学生英语核心素养[J].考试周 刊,2020(78):117-118.

[2]顾艳红.建构灵动课堂 发展数学思维[J].新课程,2020(34):131.

[3] 顾凌艳. 生活教育理念下的灵动课堂初探 [J]. 读写 算,2020(21):193+195. 